Article

\title{
Comparative Life Cycle Assessment of Cotton and Other Natural Fibers for Textile Applications
}

\author{
Angela D. La Rosa * (D) and Sotirios A. Grammatikos \\ Group of Sustainable Composites, Department of Manufacturing and Civil Engineering, Norwegian University \\ of Science and Technology, 2815 Gjøvik, Norway; sotirios.grammatikos@ntnu.no \\ * Correspondence: angela.d.l.rosa@ntnu.no; Tel.: +47-90183154
}

Received: 3 October 2019; Accepted: 15 November 2019; Published: 25 November 2019

check for updates

\begin{abstract}
Among natural fibers, such as cotton, silk, wool, flax, hemp, etc., cotton is the one that takes up the highest percentage in the textile market. Nevertheless, there are obstacles associated with its cultivation; it is restricted to sub-tropical climates, and it is dependent upon high amounts of water, as well as the use of agrochemicals to ensure good yields. The use of pesticides and other types of chemical products give a negative impact on the environment. Life cycle assessment (LCA) is used in the present study in order to evaluate the environmental impacts of cotton cultivation and fibers production for textiles. Comparisons among traditional and organic cropping have been carried out. Further comparisons are described with other natural fibers, such as jute, hemp and kenaf, in order to identify the strong and weak points of each product. Weak (e.g., lack of supply, transportation and storage of biomass, infancy of the value chain, lack of production/distribution chains, etc.) and strong aspects (e.g., market potential, rural development, environmental benefits, etc.) are considered for the production of each type of fiber.
\end{abstract}

Keywords: organic cotton; hemp fiber; environmental impact; life cycle assessment (LCA)

\section{Introduction}

\subsection{The Cotton Industry and the Environment}

According to the report "Life Cycle Assessment (LCA) of Organic Cotton" on behalf of Textile Exchange [1], organic cotton farming worldwide produces approximately 110,000 th of fibers, grown in 18 countries around the globe, of which the top five countries make up over $95 \%$ of the total, and India alone close to $75 \%$. The reason why it is extremely important to extend the organic cropping is the significant environmental problems caused by traditional cotton cultivation. The use of pesticides in several developing countries is a primary concern. Traditional cotton cultivation has been estimated to consume $11 \%$ of the world's pesticides, while it is grown on only $2.4 \%$ of the world's total arable land [2]. In developing countries, it is estimated that approximately 50\% of all pesticides are applied in cotton cultivation. In addition, pesticide use and storage are often badly managed.

Moreover, traditional cotton cultivation requires large amounts of water. Intensive irrigation is used in areas where normal precipitation quantities do not match the requirements for the cropping. From literature data it was found that $53 \%$ of cotton fields worldwide are irrigated, because irrigation generally allows higher yields per unit of area [3]. The most commonly used irrigation system for cotton cultivation is the flood-or-furrow, which, although the easiest to install, has the lowest water efficiency. In the major leading cotton producing countries, it has been found that cotton cultivation areas are significantly affected by salinization [4]. Soil salinization occurs when evapo-transpiration exceeds rainfall and represents a threat for irrigated areas in particular. 
Irrigation water dissolves calcium carbonate $\left(\mathrm{CaCO}_{3}\right)$ and soluble salts in the soil. Since calcium carbonate is relatively insoluble, it accumulates in the topsoil, leading to additional salt deposition (originally from the irrigation water) and water logging.

Regarding the energy consumption, cotton production requires a set of processes with a great use of energy. Cotton processing is largely mechanized, although in some parts of the world cotton is still harvested by hand. Specialized machinery has been developed for the harvesting of seed cotton, which either leaves the plants on the field, or returns the trash after stripping. It is important for the fiber quality that the leaves are removed, so application of chemicals for defoliation is common practice.

These are all good reasons to keep looking at other possibilities to reduce the impacts of cotton cultivation and production. The main advantage of cotton in textiles is that its market is already well organized and still developing. Organic cotton production seems to have managed to reduce consistently the environmental impact associated with the cotton market [1]. A possible intervention could be reducing water consumption by replacing cotton with either forest-based or recycled, regenerated cellulose fibers. Another solution to reduce climate impact could be to switch to renewable energy in the textile manufacturing processes [5].

\subsection{Potential Alternatives}

Among the alternatives that offer both sustainable and economic appeal, there is a group of fibers known as bast fibers. Bast is the outer part of the plant stem containing the epidermis, cortex and phloem bundles. The term bast is used to describe a number of natural fibers that can be extracted from the stem of certain plants, such as jute, flax, hemp and stinging nettle. Recent advances in technology are starting to allow bast fibers to be processed and used with other natural materials to create new economically viable fabrics [6].

Bast fiber crops, such as flax and hemp, can be grown in a more moderate climate and require low input for high yields. The hemicellulose content of these fibers contributes to breathability and thermal insulation, both of which are excellent features of textiles. Although cultivation of flax and hemp and the use of their fibers have already been described in ancient times, their importance has declined during the past few centuries as cotton has been favored.

Hemp is more durable than cotton and requires half amount of water and land that it takes to grow cotton, whereas the crop can be harvested in 90 days. It is also able to be grown without the use of any herbicides and pesticides on smaller areas of land, and can be used to create a durable, sustainable, renewable and flame retardant fabrics.

Traditional cultivation of hemp has almost disappeared from developed countries. It is still grown in some of the Asian and Eastern European countries, thanks to the low labor cost. Traditionally, hemp has been grown for its long bast fibers, which were used for producing clothing, linen, ropes and sails. Nowadays the potential applications of hemp as an industrial crop are many. Among the commercial applications of hemp fiber in the textile industry, hemp is used in the paper, building materials, bio-plastics and other industries. Hemp is an ideal rotation crop due to its long taproot structure that helps retain topsoil, while also replenishing soil quality due to the natural leaf composting that regenerates vital elements in the soil. Furthermore, hemp has the unique inherent characteristic of suppressing the growth of harmful bacteria and fungi, and is commonly used as a deterrent to insects and infestations. Hemp does not require irrigation unlike other natural fibers. As a result of the above, hemp does not require organic growing certification [7].

Life cycle assessment has been increasingly adopted by textile companies. Many actors in the textile and clothing chain, such as fiber manufacturers (e.g., Lenzing, Austria; Advansa, Germany; Dupont, global locations), producers of flooring material (e.g., InterfaceFlor, UK; Desso, UK, fashion brands (united in the Sustainable Apparel Coalition), and even umbrella organizations (European Commission and the Dutch branch organization Modint) use LCA to assess the environmental impacts of textile-related products [8,9]. The present LCA study is a contribution to broaden the information already available in literature and aims at conceiving new ideas in the textile sector. 


\section{Materials and Methods}

\section{Rationale of the Work}

A cradle-to-gate impact assessment was carried out using different data sources as listed below:

1. Average data, from the database Ecoinvent 3 provided by the software SimaPro (version 8.0.5.13, PRé Consultants, The Netherlands), were used for the evaluation of the impacts of the cultivation phase and the yarn production of the following fibers: cotton, kenaf, jute.

2. Literature from life cycle impact assessment (LCIA) results were used for the impact of organic cotton cultivation and production;

3. Literature data were used for the comparison with hemp cultivation and fiber production.

Two different functional units are considered:

- $\quad$ Functional unit 1: $1 \mathrm{~kg}$ of fiber (cotton, kenaf and jute)

- $\quad$ Functional unit 2: $1 \mathrm{~kg}$ of textile (cotton, kenaf and jute)

System boundaries for functional unit 1 include cultivation, harvesting and ginning. System boundaries for functional unit 2 include cultivation, harvesting, ginning and yarn production. Impacts evaluated for fibers production include cultivation, harvesting and ginning processes; impacts calculated for textile production takes into account all the steps from cultivation to yarn manufacturing that includes cleaning and sorting, spinning, pre-treatment, dyeing, finishing, washing and drying. They were chosen in this way to compare the processes relating to the fibers cultivation and that relating to the yarn manufacture, in order to understand which step created the highest impacts for all the fibers under investigation.

A schematic representation of the main processes referring to cotton manufacture is illustrated in Figure 1, whereas similar schematics were adopted for the other fibers under investigation.

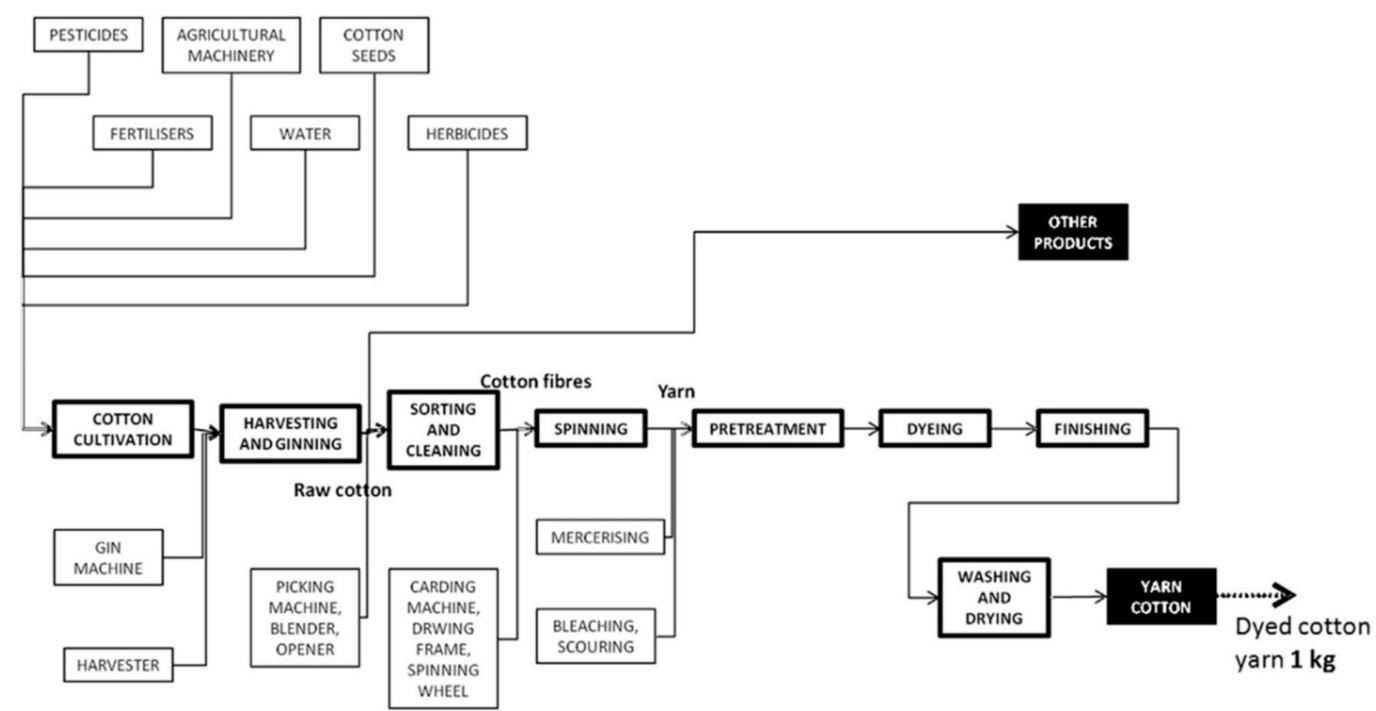

Figure 1. Scheme of the whole production process of cotton yarn. Reproduced from [6], Bevilacqua: 2014.

\section{Results}

\section{LCA Results and Discussion}

Table 1 reports the cumulative energy required (CED) results for the production of $1 \mathrm{~kg}$ of cotton, jute and kenaf fibers (cultivation, harvesting and ginning) and $1 \mathrm{~kg}$ of cotton, jute and kenaf textile (production of yarn, considering all the steps from cultivation to spinning and drying). Data were taken from the Ecoinvent 3 databased and elaborated through the SimaPro 8.0.5.13 software by the authors. 
Table 1. Cumulative energy demand for the production of $1 \mathrm{~kg}$ of fibers (cultivation) and $1 \mathrm{~kg}$ of textile (yarn).

\begin{tabular}{ccccccc}
\hline \multirow{2}{*}{$\begin{array}{c}\text { Cumulative Energy Demand } \\
\text { (CED) (MJ) }\end{array}$} & \multicolumn{2}{c}{ COTTON } & \multicolumn{2}{c}{ JUTE } & \multicolumn{2}{c}{ KENAF } \\
\cline { 2 - 7 } & Fiber & Textile & Fiber & Textile & Fiber & Textile \\
\hline & 68.5 & 368 & 29.55 & 97 & 31 & 98.5 \\
\hline
\end{tabular}

From a primary screening, the high consumption of energy for the cotton production is evident, both for the cultivation (fiber) and the yarn production (textile). The main contribution is associated with the manufacturing step, as the CED increases from 68.5 MJ for the cultivation of the fiber to $368 \mathrm{MJ}$ for the manufacture of the yarn. A much smaller increase is reported for jute and yarn textiles. Cleaning, sorting and spinning provide the highest contribution in energy consumption. Spinning is the process of converting fibers into yarn, and is the production step that uses the most energy.

According to a study conducted by Velden et al. [8] on a set of textiles (cotton, PET, nylon, acryl and elastane) it was reported that the environmental burden is not only a function of the base materials, but also of the thickness of the yarn. The authors propose that the environmental burden of spinning, weaving and knitting is a function of $1 /$ yarn size. The cradle-to-grave analysis from raw material extraction to discarded textile demonstrates that textiles made out of acryl and PET have the least impact on the environment, followed by elastane, nylon and cotton. The use phase has less relative impact than is suggested in the classical literature. The impact of spinning and weaving is relatively high (for yarn thicknesses of less than $100 \mathrm{dtex}$ ), and from the environmental point of view, knitting is better than weaving [8].

Table 2 reports interesting results, calculated in the present study, on other impact categories that are considered the most significant for this case. Water consumption is the main concern for the cotton industry. As reported in Table 2, the amount of water consumed for the production of $1 \mathrm{tn}$ of cotton textile (yarn) is $1736 \mathrm{~m}^{3}$. The water depletion for jute textile and kenaf textile is much less (188 and $257 \mathrm{~m}^{3}$, respectively). Eutrophication and acidification are also very intense for cotton textiles.

Table 2. Main impact categories evaluated for the production of $1 \mathrm{tn}$ of cotton textile, jute textile and kenaf textile.

\begin{tabular}{cccccc}
\hline Category & Unit & Method & $\begin{array}{c}\text { Cotton } \\
\text { Textile }\end{array}$ & $\begin{array}{c}\text { Jute } \\
\text { Textile }\end{array}$ & $\begin{array}{c}\text { Kenaf } \\
\text { Textile }\end{array}$ \\
\hline $\begin{array}{c}\text { Water Resource } \\
\text { Depletion }\end{array}$ & $\mathrm{m}^{3}$ water eq & $\begin{array}{c}\text { ILCD 2011 Midpoint }+ \\
\text { V1.06/EU27 2010 }\end{array}$ & 1736 & 188 & 257 \\
\hline $\begin{array}{c}\text { Cumulative } \\
\text { Energy Demand }\end{array}$ & $\mathrm{MWh}$ & V1.09/CED & 95 & 27 & 27 \\
\hline Acidification & $\mathrm{kg} \mathrm{SO}_{2}$ eq & $\begin{array}{c}\text { CML-IA baseline } \\
\text { V3.02/West Europe, 1995 }\end{array}$ & 165 & 41 & 41 \\
\hline Eutrophication & $\mathrm{kg} \mathrm{PO}_{4}$ eq & $\begin{array}{c}\text { CML-IA baseline } \\
\text { V3.02/West Europe, 1995 }\end{array}$ & 70.84 & 14.93 & 14.72 \\
\hline
\end{tabular}

Figure 2 reports schematically the results for all the impact categories evaluated for the whole production of $1 \mathrm{tn}$ of cotton, jute and kenaf textiles. The quantitative amounts associated with each impact category indicated in Figure 2 are reported in Table 3. For each impact category there is a large difference between the cotton textile and the other two fibers: jute and kenaf textiles perform almost the same values that are much lower that the amounts evaluated for cotton. 


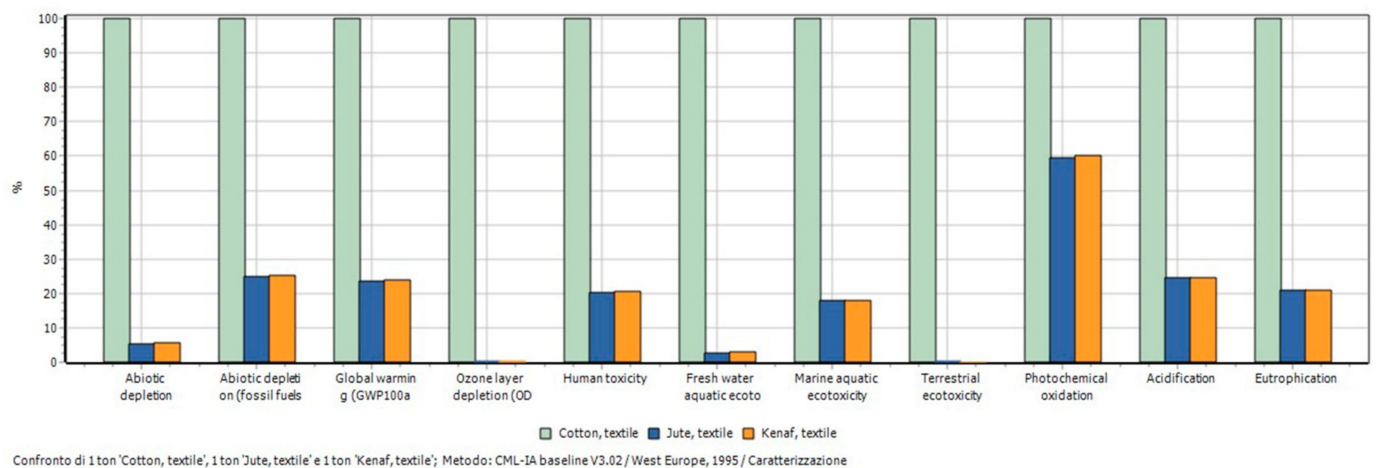

Figure 2. Schematic results of all impact categories evaluated through the CML-V3.02 method.

Table 3. Quantitative results of all impact categories evaluated through the CML-V3.02 method.

\begin{tabular}{ccccc}
\hline Impact Category & Unit & Cotton Textile & Jute Textile & Kenaf Textile \\
\hline Abiotic depletion & $\mathrm{kg} \mathrm{Sb} \mathrm{eq}$ & 0.05 & 0.00 & 0.00 \\
Abiotic depletion (fossil fuels) & $\mathrm{MJ}$ & 227 & 56.632 & 57.797 \\
Global warming (GWP100a) & $\mathrm{kg} \mathrm{CO}$ eq & 23.395 & 5515 & 5590 \\
Ozone layer depletion (ODP) & $\mathrm{kg} \mathrm{CFC-11} \mathrm{eq}$ & 0.10 & 0.00 & 0.00 \\
Human toxicity & $\mathrm{kg} \mathrm{1,4-DB} \mathrm{eq}$ & 9570 & 1924 & 1970 \\
Fresh water aquatic ecotox & $\mathrm{kg} \mathrm{1,4-DB} \mathrm{eq}$ & 48.391 & 1353 & 1381 \\
Marine aquatic ecotoxicity & $\mathrm{kg} \mathrm{1,4-DB} \mathrm{eq}$ & 38.399 & 6.840 & 6.935 \\
Terrestrial ecotoxicity & $\mathrm{kg} \mathrm{1,4-DB} \mathrm{eq}$ & 2761 & 5.86 & 4.51 \\
Photochemical oxidation & $\mathrm{kg} \mathrm{C} 2 \mathrm{H} 4 \mathrm{eq}$ & 4.86 & 2.89 & 2.93 \\
Acidification & $\mathrm{kg} \mathrm{SO}$ eq & 165 & 41 & 41 \\
Eutrophication & $\mathrm{kg} \mathrm{PO}_{4}$ eq & 70.84 & 14.93 & 14.72 \\
\hline
\end{tabular}

The same trend is reported in Figure 3 for the impacts on Human Health, Ecosystem Quality, climate Change and Resources. For all these end-point categories the highest impact is evaluated for the cotton textiles.

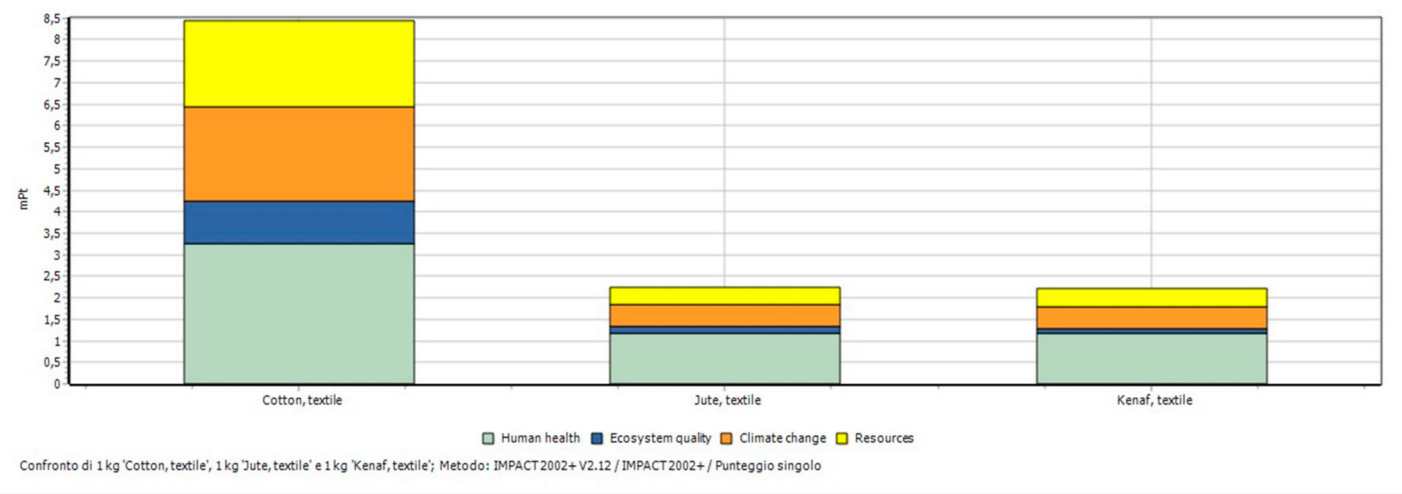

Figure 3. Impacts on Human Health, Ecosystem Quality, climate Change and Resources.

The debate about the huge impacts of cotton textile on the environment has lasted long enough to lead the cotton market towards a more sustainable production. Organic production occurs in many countries, as reported by Textile Exchanges [1]. According to this report, the global average organic cotton fiber has a primary energy demand (PED) from non-renewable resources of $5800 \mathrm{MJ}$, per $1 \mathrm{tn}$ of product at the gin gate. Non-renewable PED is an indicator of the dependence on fossil resources. The contributor analysis (Figure 4 ) shows that machinery (39\%) and ginning (33\%) are equally significant contributors. Electricity relies on coal to a large degree in many of the studied regions. 


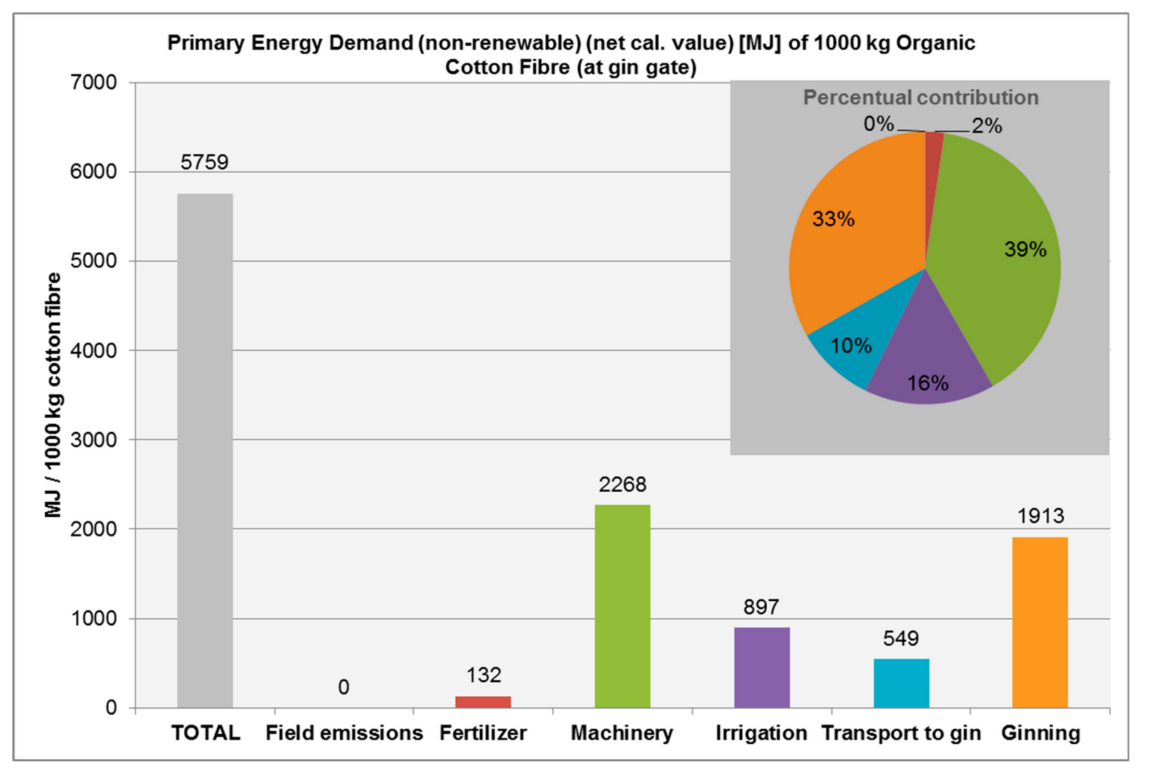

Figure 4. Energy required for cotton textiles. Reproduced from [1], Report Textile Exchanges: 2014.

Diesel, on the other hand, is used in vehicles (machinery) and pumps (irrigation), and has a higher energy to emission ratio than i.e., coal. Other fuel uses, such as irrigation and transport to the gin, are also relevant.

Interesting to note results, were also reported in [1] about the other main impact categories for organic cotton production. For $1000 \mathrm{~kg}$ of organic cotton fiber's production (at the gin gate) the following results were calculated:

- $\quad$ GWP: (978) $\mathrm{kgCO}_{2}$-eq

- $\quad$ Acidification Potential (AP): (5.7) $\mathrm{kgSO}_{2}$-eq

- $\quad$ Eutrophication Potential (EP): (2.8) $\mathrm{kgPO}_{4}{ }^{3-}$

- $\quad$ Blue water consumption: (182) $\mathrm{m}^{3}$

- $\quad$ PED (non renew): (5759) MJ

In the present study we compare, in Table 4, the main impact categories for traditional cotton fiber production and traditional kenaf and jute fiber production (all data are taken from the Ecoinvent 3 database provided by SimaPro 8.05.13). Unfortunately, the Ecoinvent database does not contain data for the organic production of these fibers. The difference of the impacts among the cotton fiber and the other two fibers under investigation are impressive, with the traditional cotton fiber resulting in being much more impacting than the others. A comparison of the main impacts evaluated for the traditional cultivation for cotton (Table 4) and the impacts found in literature [1] for the organic cotton cultivation are reported in Table 5. The results are in favor of the organic cotton cultivation.

Table 4. Main impact categories for traditional production of cotton, jute and kenaf textiles.

\begin{tabular}{cccccccc}
\hline Impact Category & Unit & \multicolumn{2}{c}{ Cotton } & \multicolumn{2}{c}{ Jute } & \multicolumn{2}{c}{ Kenaf } \\
\hline & & Fiber & Textile & Fiber & Textile & Fiber & Textile \\
\hline Terrestrial acid/nutri & $\mathrm{kg} \mathrm{SO}$ eq & 154 & 562 & 57 & 162 & 52 & 158 \\
Land occupation & m2org.arable & 7261 & 8290 & 1210 & 1603 & 1040 & 1403 \\
Aquatic acidification & $\mathrm{kg} \mathrm{SO}$ eq & 28 & 163 & 7.7 & 41 & 7.5 & 41 \\
Aquatic eutrophication & $\mathrm{kg} \mathrm{PO4P-lim}$ & 2 & 6.8 & 2.3 & 3.6 & 2.3 & 3.5 \\
Global warming & $\mathrm{kg} \mathrm{CO}$ eq & 2446 & 20.338 & 294 & 5032 & 360 & 5110 \\
Non-renew. Energy & MJ primary & 32.643 & 279.777 & 2776 & 60.935 & 3873 & 62.223 \\
Mineral extraction & MJ surplus & 149 & 1116 & 20 & 69 & 29 & 80 \\
\hline
\end{tabular}


Table 5. Main impact categories for the organic and traditional production of cotton.

\begin{tabular}{ccc}
\hline Impact Category & Organic Cotton (1000 kg) & Traditional Cotton (1000 $\mathbf{~ k g )}$ \\
\hline$(\mathrm{GWP}) \mathrm{kgCO}_{2}$ eq & 978 & 2446 \\
(Non-renew. Energy) MJ & 5759 & 32.643 \\
(Acidification) $\mathrm{kgSO}_{2}$ eq & 5.7 & 28 \\
\hline
\end{tabular}

Another interesting consideration is that the impacts evaluated for the organic cotton are close (but still higher) to the impacts evaluated for the jute and kenaf fibers in Table 4 (under the columns Fiber). Unfortunately, the Ecoinvent 3 database does not report any inventory data for the hemp fiber production. It is possible to assume that hemp fiber impacts are very close to kenaf or jute fibers, as they are very similar plants.

Furthermore, hemp plant is much more resistant than any other natural plant, and with high probability, the impacts of hemp cropping would result lower than jute and kenaf. Under these considerations, it is possible to suppose that the impacts associated with the production of hemp fibers would reasonably be lower than the impacts accounted for organic cotton. It is important to consider the possibility to develop the market for the hemp fibers for many reasons.

Firstly, hemp fibers have superior mechanical performance compared to other natural fibers. Several applications have been developed e.g.: in the polymer composite sector [10,11].

Secondarily, hemp cultivation brings environmental benefits (no use of pesticide, fertilizers and water). Unfortunately, the hemp market has still many weak points: the lack of supply due to legal and/or regulatory issue, the "THC/marijuana" problem, hinders the continuous production/distribution chain. Industrial hemp is still illegal to grow in most parts of the world, despite the best efforts by activists, businesses, farmers and organizations like Vote Hemp in the US and others to get laws changed and disassociate the versatile plant from marijuana. Currently, the world's leading producer of hemp is China, while production takes place in Europe, Chile and North Korea on a small scale. In the European Union (EU), hemp is grown on around 15,000 hectares of land, with major producers being France, Germany and the UK.

All LCA results depend on the quality of the inventory data that are available. In order to improve the reliability of the LCA results, further LCI data studies on textiles and garments are needed to lower the uncertainties in contemporary LCA of textile materials and products $[8,9]$.

\section{Conclusions}

Currently, in the textile industry, the optimum solution to reduce the high environmental impact associated with cotton fibers is to shift towards organic cotton cultivation, as the amount of water and energy consumption is lower than that for the traditional cultivation. Due to fact that the organic cultivation exhibits a reduced cropping yield, it might result into an inability to cover the market's need. In order to avoid this risk it is advisable to develop, in parallel, new markets for other natural fibers suitable for textiles, such as hemp and jute. Hemp has proven promising, however legal and regulatory issues, together with the lack of supply due to its infancy in the product market, block its further exploitation in the market of fibers.

Author Contributions: Conceptualization, A.D.L.R.; Methodology, A.D.L.R.; Software, A.D.L.R.; Writing-Original Draft Preparation, A.D.L.R.; Writing-Review \& Editing, A.D.L.R. and S.A.G.

Conflicts of Interest: The authors declare no conflict of interest.

\section{References}

1. Report, Textile Exchanges. 2014. Available online: https://textileexchange.org/downloads/life-cycleassessment-of-organic-cotton/ (accessed on 15 November 2019).

2. Scheffer, M.R. A sustainable vision on the cotton industry after 2005. In Proceedings of the Speech Held at the General Assembly of EUROCOTON, Brussels, Belgium, 30 May 2001. 
3. Clay, J. World Agriculture and the Environment. In Cotton Incorporated; Island Press: Washington, DC, USA, 2009. Available online: http://www.cottoninc.com/ (accessed on 15 November 2019).

4. Stockle, C.O. Environmental Impact of Irrigation: A Review. 2001. Available online: http://citeseerx.ist.psu. edu/viewdoc/download?doi=10.1.1.488.4861\&rep=rep1\&type=pdf. (accessed on 15 November 2019).

5. Roos, S.; Zamani, B.; Sandin, G.; Peters, G.M.; Svanstrom, M. A life cycle assessment (LCA)-based approach to guiding an industry sector towards sustainability: The case of the Swedish apparel sector. J. Clean. Prod. 2016, 133, 691-700. [CrossRef]

6. Bevilacqua, M.; Ciarapica, F.E.; Mazzuto, G.; Paciarotti, C. Environmental analysis of a cotton yarn supply chain. J. Clean. Prod. 2014, 82, 154-165. [CrossRef]

7. Summerscales, J.; Dissanayakea, N.P.J.; Virka, A.S.; Hal, W. A Review of Bast Fibers and their Composites. Part 1-Fibers as reinforcements. Compos. Part A Appl. Sci. Manuf. 2010, 41, 1329-1335. [CrossRef]

8. Velden, N.M.; Patel, M.K.; Vogtlander, J.G. LCA benchmarking study on textiles made of cotton, polyester, nylon, acryl, or elastane. Int. J. Life Cycle Assess. 2013. [CrossRef]

9. Peters, G.; Svanström, M.; Roos, S.; Sandin, G.; Zamani, B. Handbook of Life Cycle Assessment (LCA) of Textiles and Clothing; Woodhead Publishing Series in Textiles; Elsevier: Amsterdam, The Netherlands, 2015.

10. La Rosa, A.D.; Cozzo, G.; Latteri, A.; Recca, A.; Björklund, A.; Parrinello, E.; Cicala, G. Life cycle assessment of a novel hybrid glass-hemp/thermoset composite. J. Clean. Prod. 2013, 44, 69-76. [CrossRef]

11. La Rosa, A.D.; Summerscales, J.; Recca, G.; Latteri, A.; Cozzo, G.; Cicala, G. Bio-based versus traditional polymer composites. A life cycle assessment perspective. J. Clean. Prod. 2014, 74, 135-144. [CrossRef]

(C) 2019 by the authors. Licensee MDPI, Basel, Switzerland. This article is an open access article distributed under the terms and conditions of the Creative Commons Attribution (CC BY) license (http://creativecommons.org/licenses/by/4.0/). 